\title{
STATUS OF BIODIVERSITY OF MAHAWELI RIVER AND ITS RIVER BANKS BETWEEN WATAWALA AND GINIGATHHENA
}

\author{
K L M Chandrakanthie, D K N G Pushpakumara, R H G Ranil, \\ D M M Pradeepa, and K C PKumara. \\ Faculty of Agriculture, University of Peradeniya
}

\begin{abstract}
A systematic survey was conducted from January to August 2003 to identify existing major habitats, status of biodiversity with respect to flora (flowering plants and fern and fern allies) and fauna (birds and mammals, butterflies, amphibians and freshwater fish species), and threats they faced in the Mahaweli river and adjacent river banks between Watawala and Nawalapitiya. The flora and fauna were documented using scientifically valid techniques.
\end{abstract}

The survey enabled to identify seven major vegetation/habitats along the Mahaweli river and its adjacent river banks. They are: river bank habitat with secondary growth; flowing fresh water habitat; ephemeral and perennial small stream water habitat; scrub forest area; Pinus plantation, homegardens, Albizia dominated abandoned tea plantation, tea plantation, abandoned tea plantation with grassland, and Eucalyptus plantation. Within the stretch, a total of 170 species of flowering plants and fern and fern allies belongs to 64 families were identified. A total of 18 species of birds ( 9 families), 16 species of butterflies ( 7 families), 10 species of freshwater fishes ( 5 families), 16 species of reptiles ( 7 families), 7 species of amphibians ( 3 families) and 13 species of mammals (10 families) have also been documented.

At present, the biodiversity of Mahaweli river and its adjacent river banks has been subjected to several threats, namely pollution due to garbage disposal (mainly at Ginigathhena), spread of alien invasive species (mainly at river banks due to Clusia rosea), direct exploitation of species (freshwater fish species), encroachment of bank reservation, unplanned land use practices and small hydropower projects. The critically affected group as a result of these threats is fresh wa.er fish species, which includes 6 threatened endemic species. Thus, clear mitigatory measures will be required to avoid disturbances to such species.

Proceedings of the Ninth Annual Forestry and Environment Symposium 2003 of the Department of Forestry and Environmental Science, University of Sri Jayewardenepura. Sri Lanka 